\title{
Cyber violence pattern and related factors: online survey of females in Egypt
}

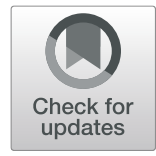

\author{
Fatma Mohamed Hassan ${ }^{1 *}$ (D) Fatma Nada Khalifa', Eman D. El Desouky ${ }^{2}$, Marwa Rashad Salem ${ }^{3}$ and \\ Mona Mohamed Ali ${ }^{1,4}$
}

\begin{abstract}
Background and objectives: Cyber violence against women and girls is an emerging worldwide problem with a grave impact on individuals and societies. This study aimed to assess the problem of cyber violence against women among the Egyptian population.

Methods: A convenience sampling method was used to recruit a total of 356 females. A self-completion questionnaire was distributed through one of the social media applications.

Results: About $41.6 \%$ of the participants experienced cyber violence during the last year, and $45.3 \%$ of them reported multiple times of exposure. Social media was the most common way of exposure, and the offenders were unknown for $92.6 \%$ of the victims. The most commonly reported forms included $41.2 \%$ receiving images or symbols with sexual content, $26.4 \%$ receiving insulting e-mails or messages, $25.7 \%$ receiving offensive or humiliating posts or comments, $21.6 \%$ receiving indecent or violent images that demean women, and $20.3 \%$ receiving infected files through e-mails. The majority of the victims (76.9\%) experienced psychological effects in the form of anger, worry, and fear; $13.6 \%$ social effects; $4.1 \%$ exposed to physical harm; and $2.0 \%$ reported financial losses. Blocking the offender was the most common victims' response.
\end{abstract}

Conclusion: Females in the Egyptian population are highly exposed to cyber violence, so implementation of anticyber violence program is essential to counteract this phenomenon.

Keywords: Cyber violence, Cyber harassment, Women, Social media, Egypt, Survey

\section{Background}

Women across the world are subject to various forms of violence: physical, sexual, psychological, and economic regardless of their age, education, or socioeconomic classes (Habib et al. 2011; UN Broadband Commission for Digital Development Working Group on Broadband and Gender 2015). About 35\% of women worldwide had exposed to either physical and/or sexual intimate partner violence or non-partner sexual violence during their lifetime as indicated by the global estimates of WHO (WHO 2017).

A unique form of violence against women has arisen with the increased use of the Internet, social media, and the spread of information and communication technologies

\footnotetext{
* Correspondence: fatmahasan.2010@yahoo.com

'Department of Forensic Medicine and Clinical Toxicology, Faculty of

Medicine, Cairo University, Kasr Alainy Street, Cairo 11562, Egypt

Full list of author information is available at the end of the article
}

(ICT) which is cyber violence (Arafa et al. 2018). Cyber violence is an emerging worldwide phenomenon with grave public health consequences. It is not only associated with the adverse psychological, social, and reproductive health effects but also with offline physical and sexual violence for victims (Backe et al. 2018; Šincek et al. 2017).

Cyber violence against women could have many forms including cyber harassment, cyberstalking, defamation, non-consensual pornography, e-mail spoofing, cyber hacking, and virtual rape (EIGE 2017; Singh 2015).

Data about the magnitude of cyber violence and its incidence across different populations and communities are scarce, but studies suggest that online victimization is more likely to involve women, girls, and sexual minorities (Backe et al. 2018). In a survey involving more than 9000 German Internet users, women were significantly more likely than men to experience online sexual harassment and cyberstalking (Staude-Müller et al. 2012). Also, 
a Pew Research Center survey in the USA including more than 4000 adults disclosed that among subjects aged 18-29, women were more vulnerable to online sexual harassment than men (21 versus 9\%) (Duggan 2017). The European Agency for Fundamental Rights based on European Survey reported that one in 10 women had experienced a form of cyber violence since the age of 15 (European Union Agency for Fundamental Rights 2014).

In Egypt, the digital society includes 37.9 million users, and 35 million of them have active Facebook accounts, with a total number of male users 22 million, while the number of female users is 12 million (MICT 2018). However, the study of cyber violence against women has not kept up with the spread of ICT. The objective of this study was, therefore, to evaluate the problem of cyber violence against women among the Egyptian population including its prevalence, different forms, relation to sociodemographic characteristics, and impact on victims' lives.

\section{Methods}

\section{Sampling procedure}

The study was carried out using an online survey disseminated through one of the social media most frequently used in Egypt which is the Facebook application. The researchers selected groups with a large number of female members to achieve a high response rate. Requests were sent to administrators of these groups to get permission to disseminate the survey. Then, the researchers posted the link of the survey with a statement including its purpose and encouraging the members to participate. The study spanned from 1 October 2018 to 31 December 2018.

\section{Recruitment and participants}

A convenience sampling technique was followed whereby the researchers looked on Facebook for women's groups with a large female network. Once they located the groups, they disseminated announcements about the study to these groups, and a link to the study page was provided. For 3 months, this link was available on some groups where a total of 356 adult females ( $\geq 18$ years old) answered the questionnaire. The majority of the participants (63.2\%) aged between 26 and 35 years; most of them were married (68.8\%), about half of them $(48.9 \%)$ received postgraduate education, and the other half $(47.5 \%)$ had received higher education; $67.4 \%$ of them was living in Greater Cairo followed by $25.8 \%$ and $6.7 \%$ in Lower Egypt and Upper Egypt, respectively; $60.7 \%$ of them had regular work, while $29.2 \%$ were not working; and $58.1 \%$ used the Internet and mobile phones for more than $3 \mathrm{~h}$ per day.

\section{Data collection tool}

For data collection, a pre-tested self-administrated Arabic language e-form questionnaire was designed by the research team. It included two sections:

Section I: Sociodemographic data: age, marital status, educational level, residence, occupation, and mobile phone and Internet use (h/day).

Section II: Cyber violence questions, which included 14 closed-ended question items as follows: Were you exposed to any form of cyber violence in the last year? (If your answer is no, then submit the form.) What was the way to your exposure to cyber violence? How many times were you exposed to cyber violence in the last year? Were you exposed to any of these forms of cyber violence in the last year? Do you know the offender (the person who practiced cyber violence against you)? What is the offender's gender? What is the offender's age? What is your relation to the offender? What was his/her motive? What was your response to the incident? What was the impact of cyber violence on you? How were you psychologically affected? How were you socially affected? What was the community response to your exposure to cyber violence?

The original language of the included items was English; they were translated to Arabic by two experts followed by back translation to English by other independent experts. The face and content validity were examined after collecting their viewpoints of public health experts. The preliminary data collection form was tested on 12 females to assess the clarity and comprehension of questions and the time needed to answer the questionnaire, and no phrases or words were omitted.

\section{Statistical analysis}

Statistical analysis was done using the Statistical Package for the Social Sciences program (SPSS, version 21.0 IBM). The data were summarized using numbers, and percentages were used for qualitative variables. Comparison between groups was performed using the chi-square test for qualitative variables. $P$ value of less than 0.05 was considered statistically significant.

\section{Ethical considerations}

All procedures for data collection were treated with confidentiality according to Helsinki declarations of biomedical ethics. The researchers requested the informed consent of the participants after explanation of the study objectives and importance. The study page included the questionnaire, information about the purpose of the study, and informed consent. The participants were given access to the survey once provided their consent. It was clearly stated in the research announcement that 
the survey was examining cyber violence among women. Participants were informed that this was an anonymous survey and participation was voluntary.

\section{Results}

Our results revealed that $41.6 \%$ of the participating females reported exposure to cyber violence during the last year and $45.3 \%$ of the victims experienced cyber violence multiple times; the most common way of exposure as reported by about three quarters of the participants $(72.8 \%)$ was social media, and the offenders were unknown for the majority (92.6\%) of the victims as shown in Table 1. The known offenders were males in 10 cases, either current or ex-partners (4 cases) or the victim's relatives, co-workers, or friends, and the recognized motives were revenge, hate, and blackmailing.

Table 2 revealed that about one half of the enrolled participants $(41.2 \%)$ reported receiving images or symbols with sexual contents, $26.4 \%$ received insulting e-mails or messages, $25.7 \%$ received offensive or humiliating posts or comments, $21.6 \%$ received indecent or violent images that demean women, $20.3 \%$ received infected files through e-mails, and $14.9 \%$ were hacked.

Concerning the impact of cyber violence on exposed females, the majority (76.9\%) experienced psychological effects in the form of anger, worry, fear, suicidal thoughts, and desire to revenge, while $13.6 \%$ experienced social effects as withdrawal from online activity and being isolated (Table 3 ).

As shown in Table 4, blocking the offender, reporting contents, and changing the contact information were the

Table 1 Percent distribution of the enrolled females by exposure to cyber violence during the last year

\begin{tabular}{|c|c|c|}
\hline & $N$ & $\%$ \\
\hline \multicolumn{3}{|c|}{ Exposure to cyber violence during the last year } \\
\hline No & 208 & 58.4 \\
\hline Yes & 148 & 41.6 \\
\hline \multicolumn{3}{|c|}{ Number of times of exposure to cyber violence in the last year } \\
\hline Multiple times & 67 & 45.3 \\
\hline Once & 49 & 33.1 \\
\hline Twice & 32 & 21.6 \\
\hline \multicolumn{3}{|l|}{ Way of exposure ${ }^{a}$} \\
\hline Social media & 107 & 72.8 \\
\hline Mobile phone & 59 & 40.1 \\
\hline E-mail & 17 & 11.6 \\
\hline Others & 3 & 2.0 \\
\hline \multicolumn{3}{|c|}{ The offender of cyber violence } \\
\hline Known & 11 & 7.4 \\
\hline Unknown & 137 & 92.6 \\
\hline
\end{tabular}

${ }^{\mathrm{a}}$ Participants have multiple responses
Table 2 Percent distribution of the exposed females by forms of cyber violence $(N=148)$

\begin{tabular}{llc}
\hline How were you exposed $^{a}$ & $n$ & $\%$ \\
\hline Received images or symbols with sexual contents & 61 & 41.2 \\
Received mean or insulting e-mails or messages & 39 & 26.4 \\
Received offensive or humiliating posts or comments & 38 & 25.7 \\
Received indecent or violent images or videos to & 32 & 21.6 \\
demean women & 30 & 20.3 \\
Received infected file/program via e-mails & 22 & 14.9 \\
E-mail or your private accounts and web pages were hacked & 20 & 13.5 \\
Identity was stolen & 17 & 11.5 \\
Online and offline activities were monitored and tracked & 16 & 10.8 \\
Exposed to defamatory information and false messages posts & 9 & 6.1 \\
Private data and/or photos were accessed and disseminated & & \\
without your consent & 7 & 4.7 \\
Movements were tracked without consent & 6 & 4.1 \\
Received threats of physical or sexual violence & 6 & 4.1 \\
Received direct blackmail & 44 & 29.7 \\
Annoying phone calls & &
\end{tabular}

${ }^{\text {a }}$ articipants have multiple responses

most common female responses to the cyber violence incidents $(72.8,26.5$, and $25.2 \%$ respectively). While regarding the community response, $33.3 \%$ reported that their families and friends were supportive and helpful while $9.5 \%$ were asked to ignore and $5.4 \%$ were blamed.

On assessing the effects of sociodemographic characteristics on the exposure rate of cyber violence, results revealed that neither age, education, residence, occupation, nor daily Internet use had played a role in exposure to cyber violence with non-significant $p$ value, only the

Table $\mathbf{3}$ Impact of exposure to cyber violence on exposed females $(N=148)$

\begin{tabular}{llll}
\hline Among exposed $(n=148)^{a}$ & & $n$ & $\%$ \\
\hline Effect & Psychological & 113 & 76.9 \\
& Social & 20 & 13.6 \\
& Physical & 6 & 4.1 \\
& Financial & 3 & 2.0 \\
& No effect & 33 & 22.4 \\
Psychological effect & Anger & 105 & 71.4 \\
& Desire to revenge & 19 & 12.9 \\
& Worry & 52 & 35.4 \\
& Fear & 32 & 21.8 \\
& Suicidal thoughts & 5 & 3.4 \\
& Others & 2 & 1.3 \\
Social effect & Withdraw online activity & 27 & 18.5 \\
& Isolated & 16 & 11.0 \\
& Others & 4 & 2.7 \\
\hline
\end{tabular}

${ }^{\mathrm{a}}$ Participants have multiple responses 
Table 4 Female and community responses to cyber violence incidents ( $N=148)$

\begin{tabular}{|c|c|c|c|}
\hline \multicolumn{2}{|c|}{ Among exposed $(n=148)^{a}$} & \multirow{2}{*}{$\begin{array}{l}n \\
107\end{array}$} & \multirow{2}{*}{$\begin{array}{l}\% \\
72.8\end{array}$} \\
\hline Female response & Blocked the offender & & \\
\hline & Reported content to platform & 39 & 26.5 \\
\hline & Changed contact information & 37 & 25.2 \\
\hline & No response & 24 & 16.3 \\
\hline & Confronted the offender & 10 & 6.8 \\
\hline & Disconnected from online network & 7 & 4.8 \\
\hline & Others & 3 & 2.0 \\
\hline \multirow[t]{5}{*}{ Community response } & You didn't tell anyone & 51 & 34.7 \\
\hline & Family and friends were supportive and helpful & 49 & 33.3 \\
\hline & You were asked to ignore and not defend & 14 & 9.5 \\
\hline & You were blamed & 8 & 5.4 \\
\hline & No response & 26 & 17.0 \\
\hline
\end{tabular}

${ }^{\text {aParticipants have multiple responses }}$

marital status showed a significant effect $(p=0.001)$ with married females being less likely to experience it (Table 5). Also, none of these variables affected the frequency of exposure (Table 6).

\section{Discussion}

Cyber violence is a major worldwide problem that has arisen with increased use of the Internet, smartphones, and social media. This study presents an overview of cyber violence against women in Egypt.

Our results revealed that nearly half of the participating females experienced different forms of cyber violence throughout the last year with about half of them reporting multiple times of exposure. The most common forms were cyber harassment and cyberstalking represented in the following (receiving images or symbols with sexual contents, insulting e-mails or messages, receiving offensive or humiliating posts or comments, indecent or violent images that demean women, and threats of physical or sexual violence).

Our findings are lower than those of Arafa and Senosy (2017) who found that $52.9 \%$ of females participating in their study experienced cyberbullying with $69.9 \%$ reporting more than one-time exposure. They also reported that cyber harassment was the most common form. But compared to our population, their participants were university students representing specific age, and also, they conducted the study in a single governorate in Egypt.

Consistent with our result, several studies reported cyber harassment and cyberstalking for being the most common forms of cyber violence against women. A survey by Battered Women's Support Services found that about one third of the participated women had experienced online harassment or cyberstalking (West 2014). Also, research by the African Development Bank in Kenya found that more than one third of the respondents had experienced online harassment, and another third received personal hate speech, cyberbullying, and trolling and contacted by imposters (African Development Bank Group 2016).

In the current study, social media platforms were the most common way of exposure to cyber violence. This is in agreement with the Pew Research Center report that found online harassment more prevalent in some online environments than others, and that most of the incidents occurred on social networking sites (Duggan et al. 2014).

Regarding the offenders in our study, they were unknown for $92.6 \%$ of the victims. Duggan et al. (2014) reported that the perpetrators were anonymous for half of those who had experienced online harassment. On the contrary, The Association of Progressive Communications' (APC) research project "End violence: women's rights and safety online" found out that half of the perpetrators were known (APC Women's Rights Programme 2015).

In this study, out of the 11 known offenders, 10 were males. Alike, Pasricha (2016) found that $85 \%$ of their survey participants reported that the incidents were perpetrated by men or under accounts with a male name. Also, women's rights organizations' research in three of the Nordic countries (Iceland, Denmark, and Norway) described perpetrators as being typically men (Jóhannsdóttir et al. 2017). Concordant with APC's research project results, our results also revealed that the known offenders were either a current or former partner or the victim's relatives, co-workers, or friends.

This study revealed that the most common impact of cyber violence on the victims was the psychological, followed by the social, then the physical and economic impacts. It also pointed to many psychological effects including the most common: anger, worry, and fear, and the gravest-suicidal thoughts. Similarly, West (2014) found that $65 \%$ of their survey respondents reported 
Table 5 Relation between sociodemographic data and cyber violence exposure among participating females during the last year $(N=148)$

\begin{tabular}{|c|c|c|c|c|c|}
\hline \multirow[t]{3}{*}{ Sociodemographic variables } & \multicolumn{4}{|c|}{ Cyber violence exposure during the last year } & \multirow[t]{3}{*}{$P$ value } \\
\hline & \multicolumn{2}{|c|}{ Not exposed } & \multicolumn{2}{|c|}{ Exposed } & \\
\hline & $n$ & $\%$ & $n$ & $\%$ & \\
\hline \multicolumn{6}{|l|}{ Age group } \\
\hline$\leq 35$ years & 173 & 58.4 & 123 & 41.6 & \multirow[t]{2}{*}{0.987} \\
\hline$>35$ years & 35 & 58.3 & 25 & 41.7 & \\
\hline \multicolumn{6}{|l|}{ Marital status } \\
\hline Divorced & 4 & 33.3 & 8 & 66.7 & \multirow[t]{4}{*}{$0.001^{*}$} \\
\hline Married & 160 & 65.3 & 85 & 34.7 & \\
\hline Single & 44 & 44.9 & 54 & 55.1 & \\
\hline Widow & 0 & 0.0 & 1 & 100.0 & \\
\hline \multicolumn{6}{|l|}{ Educational level } \\
\hline Basic level & 2 & 50.0 & 2 & 50.0 & \multirow[t]{4}{*}{0.925} \\
\hline Higher education & 100 & 59.2 & 69 & 40.8 & \\
\hline Postgraduate & 100 & 57.5 & 74 & 42.5 & \\
\hline Secondary level & 6 & 66.7 & 3 & 33.3 & \\
\hline \multicolumn{6}{|l|}{ Residence governorate } \\
\hline Greater Cairo & 138 & 57.5 & 102 & 42.5 & \multirow[t]{3}{*}{0.236} \\
\hline Lower Egypt & 59 & 64.1 & 33 & 35.9 & \\
\hline Upper Egypt & 11 & 45.8 & 13 & 54.2 & \\
\hline \multicolumn{6}{|l|}{ Occupation } \\
\hline Irregular work & 19 & 52.8 & 17 & 47.2 & \multirow[t]{3}{*}{0.765} \\
\hline Not working & 61 & 58.7 & 43 & 41.3 & \\
\hline Regular work & 128 & 59.3 & 88 & 40.7 & \\
\hline \multicolumn{6}{|c|}{ Mobile phone and Internet use (h/day) } \\
\hline $0-1 \mathrm{~h}$ & 11 & 73.3 & 4 & 26.7 & \multirow[t]{4}{*}{0.174} \\
\hline $1-2 \mathrm{~h}$ & 31 & 70.5 & 13 & 29.5 & \\
\hline $2-3 h$ & 52 & 57.8 & 38 & 42.2 & \\
\hline$>3 \mathrm{~h}$ & 114 & 55.1 & 93 & 44.9 & \\
\hline
\end{tabular}

${ }^{*} P$ is statistically significant

being psychologically affected. Moreover, Lenhart et al. (2016) found that women were more likely than men to be angry, worried, and scared.

Regarding the female response to the cyber violence incidents in this study, they commonly responded by blocking the offender, reporting contents to platforms, and changing their contact information. Likewise, previous studies showed that the same finding (African Development Bank Group 2016; Duggan et al. 2014; Pasricha 2016). Surprisingly, none of the victims in our study reported the incidents to the police. Lewis et al. (2017) mentioned that victims might think these incidents are personal issues and their reputation might be damaged by reporting and making it public. Also, unawareness of the laws that condemn cyber violence may play a role.

In this study, about one third of the victims did not tell anyone about their exposure to cyber violence. The conservative nature of our community and the fear of shame, disgrace, or blame that may arise after disclosing their experience even to families or friends may be the cause.

About the impact of the studied sociodemographic factors on the rate and frequency of exposure to cyber violence, we found that the only significant finding with cyber violence exposure was the marital status; married females were significantly less exposed. We expect that married females are less likely to engage in social networking and that they are more careful in their social activities which make them less likely to cyber violence exposure. Moreover, offenders might think married women have more support so avoid attacking them.

Previous research showed inconsistent results in this issue. Arafa et al. (2018) and Arafa and Senosy (2017) found that the duration of daily Internet use significantly 
Table 6 Relation between sociodemographic data and frequency of exposure to cyber violence among participating females during the last year $(N=148)$

\begin{tabular}{|c|c|c|c|c|c|c|c|}
\hline \multirow[t]{3}{*}{ Sociodemographic variables } & \multicolumn{6}{|c|}{ Frequency of exposure to cyber violence during the last year } & \multirow[t]{3}{*}{$P$ value } \\
\hline & \multicolumn{2}{|c|}{ Multiple times } & \multicolumn{2}{|c|}{ Once } & \multicolumn{2}{|c|}{ Twice } & \\
\hline & $n$ & $\%$ & $n$ & $\%$ & $n$ & $\%$ & \\
\hline \multicolumn{8}{|l|}{ Age group } \\
\hline$\leq 35$ years & 58 & 47.2 & 40 & 32.5 & 25 & 20.3 & \multirow[t]{2}{*}{0.545} \\
\hline$>35$ years & 9 & 36.0 & 9 & 36.0 & 7 & 28.0 & \\
\hline \multicolumn{8}{|l|}{ Marital status } \\
\hline Divorced & 6 & 75.0 & 1 & 12.5 & 1 & 12.5 & \multirow[t]{4}{*}{0.303} \\
\hline Married & 32 & 37.6 & 33 & 38.8 & 20 & 23.5 & \\
\hline Single & 28 & 51.9 & 15 & 27.8 & 11 & 20.4 & \\
\hline Widow & 1 & 100.0 & 0 & 0.0 & 0 & 0.0 & \\
\hline \multicolumn{8}{|l|}{ Educational level } \\
\hline Basic level & 2 & 100.0 & 0 & 0.0 & 0 & 0.0 & \multirow[t]{4}{*}{0.521} \\
\hline Higher education & 31 & 44.9 & 20 & 29.0 & 18 & 26.1 & \\
\hline Postgraduate & 32 & 43.2 & 28 & 37.8 & 14 & 18.9 & \\
\hline Secondary level & 2 & 66.7 & 1 & 33.3 & 0 & 0.0 & \\
\hline \multicolumn{8}{|l|}{ Residence governorate } \\
\hline Greater Cairo & 46 & 45.1 & 31 & 30.4 & 25 & 24.5 & \multirow[t]{3}{*}{0.618} \\
\hline Lower Egypt & 14 & 42.4 & 14 & 42.4 & 5 & 15.2 & \\
\hline Upper Egypt & 7 & 53.8 & 4 & 30.8 & 2 & 15.4 & \\
\hline \multicolumn{8}{|l|}{ Occupation } \\
\hline Irregular work & 5 & 29.4 & 7 & 41.2 & 5 & 29.4 & \multirow[t]{3}{*}{0.72} \\
\hline Not working & 21 & 48.8 & 13 & 30.2 & 9 & 20.9 & \\
\hline Regular work & 41 & 46.6 & 29 & 33.0 & 18 & 20.5 & \\
\hline \multicolumn{8}{|c|}{ Mobile phone and Internet use (h/day) } \\
\hline$>3 \mathrm{~h}$ & 46 & 49.5 & 26 & 28.0 & 21 & 22.6 & \multirow[t]{4}{*}{0.459} \\
\hline $0-1 \mathrm{~h}$ & 2 & 50.0 & 2 & 50.0 & 0 & 0.0 & \\
\hline $1-2 h$ & 3 & 23.1 & 6 & 46.2 & 4 & 30.8 & \\
\hline $2-3 \mathrm{~h}$ & 16 & 42.1 & 15 & 39.5 & 7 & 18.4 & \\
\hline
\end{tabular}

associated with exposure and frequency of exposure to cyber violence. Also, Winkelman et al. (2015) found that age significantly associated with exposure and they reported that women who had been threatened via text or instant messaging were significantly older compared to those who were not victimized in this area.

\section{Limitations}

This study had some limitations. The study population may not be representative of the female population in Egypt as the study targeted only women with an online presence on Facebook. Besides, the study included only victims, not offenders or witnesses of cyber violence. Also, participation in the study relied on self-report data, and therefore, response bias on cyber violence would over-represent those who had been victimized and those severely affected. However, this study could contribute to the limited research published on this topic and be a base for more comprehensive studies that explore cyber violence against women.

\section{Conclusion and recommendation}

In conclusion, a high rate of cyber violence against women had been detected among the Egyptian population in the past year. Consequently, it is urgent that the government enact strong laws that criminalize cyber violence in its various forms. It is also essential to arrange awareness programs for women how to maintain their online personal safety, protect their identity, and how to deal with cyber violence incidents. In addition, media awareness campaigns should be raised to change the attitude of society towards women exposed to cyber violence. Finally, further research should be conducted to get adequate women's representations of this problem and detect awareness-raising needs. 


\section{Abbreviations}

APC: Association of Progressive Communications; ICT: Information and Communication Technologies; SPSS: Statistical Package for the Social Sciences program; WHO: World Health Organization

\section{Acknowledgements}

None.

\section{Authors' contributions}

FMH: designing the study and writing of the manuscript. FNK: collecting the data. EDED and MRS: analyzing the data and finalizing the methodology and tools used. MMA: final and critical revision of the manuscript. All the authors made significant contributions in finalizing the manuscript. The final manuscript has been read and approved by all the authors.

\section{Funding}

None.

\section{Availability of data and materials}

The datasets supporting the conclusions of this article are included within the article.

\section{Ethics approval and consent to participate}

The study was approved by the Ethical Committee of Faculty of Medicine, Cairo University. All procedures for data collection were treated with confidentiality according to Helsinki declarations of biomedical ethics. The researchers requested the informed consent of the participants after explanation of the study objectives and importance. Participants were informed that this was an anonymous survey and participation was voluntary.

\section{Consent for publication}

Not applicable.

\section{Competing interests}

The authors declare that they have no competing interests.

\section{Author details}

'Department of Forensic Medicine and Clinical Toxicology, Faculty of Medicine, Cairo University, Kasr Alainy Street, Cairo 11562, Egypt.

${ }^{2}$ Department of Epidemiology and Biostatistics, Faculty of Medicine, National Cancer Institute, Cairo University, Kasr Alainy Street, Cairo 11562, Egypt. ${ }^{3}$ Department of Public Health and Community Medicine, Faculty of Medicine, Cairo University, Kasr Alainy Street, Cairo 11562, Egypt. ${ }^{4}$ Forensic Medicine and Clinical Toxicology, Faculty of Medicine, Taif University, Ta'if, Saudi Arabia.

Received: 12 November 2019 Accepted: 28 January 2020 Published online: 10 February 2020

\section{References}

African Development Bank Group (2016) Minding the gaps: identifying strategies to address gender-based cyber violence in Kenya. https://www.afdb.org/ fileadmin/uploads/afdb/Documents/Generic-Documents/Policy_Brief_on_ Gender_Based_Cyber_Violence_in_Kenya.pdf. Accessed 12 Dec 2018.

APC Women's Rights Programme (2015) Briefing paper on VAW. https://www. apc.org/sites/default/files/HRC\%2029\%20VAW\%20a\%20briefing\%20paper_ FINAL June\%202015.pdf. Accessed 3 Mar 2019.

Arafa AE, Elbahrawe RS, Saber NM, Ahmed SA, Abbas AM (2018) Cyber sexual harassment: a cross-sectional survey over female university students in Upper Egypt. Int J Community Med Public Health 5(1):61-65. https://doi.org/10. 18203/2394-6040.ijcmph20175763

Arafa AE, Senosy SA (2017) Pattern and correlates of cyberbullying victimization among Egyptian university students in Beni-Suef, Egypt. J Egypt Public Health Assoc 92(2):107-115. https://doi.org/10.21608/epx.2018.8948

Backe EL, Lilleston P, McCleary-Sills J (2018) Networked individuals, gendered violence: a literature review of cyber violence. Violence Gender 5(3):135-145. https://doi.org/10.1089/vio.2017.0056

Duggan M (2017) Online harassment. Pew Research Center https://www. pewinternet.org/2017/07/11/online-harassment-2017. Accessed 28 Feb 2019.
Duggan M, Rainie L, Smith A, Funk C, Lenhart A, Madden M (2014) Online harassment. Pew Research Center http://www.pewinternet.org/2014/10/22 part-1-experiencing-online-harassment/. Accessed 3 Mar 2019.

European Institute for Gender Equality (2017) Cyber violence against women and girls. https://doi.org/10.2839/876816

European Union Agency for Fundamental Rights (2014) Violence against women: an EU-wide survey - main results. https:/fra.europa.eu/sites/default/files/fra_ uploads/fra-2014-vaw-survey-main-results-apr14_en.pdf. Accessed 10 Mar 2019.

Habib SR, Abdel Azim EK, Fawzy IA, Kamal NN, El Sherbini AM (2011) Prevalence and effects of violence against women in a rural community in Minia Governorate, Egypt. J Forensic Sci 56(6):1521-1527. https://doi.org/10.1111/j. 1556-4029.2011.01886.x

Jóhannsdóttir A, Aarbakke MH, Nielsen RT (2017) Online violence against women in the nordic countries. http://www.kun.no/uploads/7/2/2/3/72237499/2017_ onlineviolence_web.pdf. Accessed 12 Mar 2019.

Lenhart A, Ybarra M, Zickuhr K, Price-Fenney M (2016) Online harassment, digital abuse, and cyberstalking in America. Data \& Society https://www.datasociety. net/pubs/oh/Online_Harassment_2016.pdf. Accessed 20 Jan 2019

Lewis R, Rowe M, Wiper C (2017) Online abuse of feminists as an emerging form of violence against women and girls. Br J Criminol 57(6):1462-1481. https://doi.org/10.1093/bjc/azw073

Pasricha J (2016) Violence online in India: cybercrimes against women \& minorities on social media. https://feminisminindia.com/wp-content/ uploads/2016/05/FIl_cyberbullying_report_website.pdf. Accessed 20 Feb 2019.

Šincek D, Duvnjak I, Milić M (2017) Psychological outcomes of cyber-violence on victims, perpetrators and perpetrators/victims. Hrvatska revija za rehabilitacijska istraživanja 53(2):98-110. https://doi.org/10.31299/hrri.53.2.8

Singh J (2015) Violence against women in cyber world: a special reference to India. Int J Adv Res Manag Soc Sci 4(1):60-76

Staude-Müller F, Hansen B, Voss M (2012) How stressful is online victimization? Effects of victim's personality and properties of the incident. Eur J Dev Psychol 9(2):260-274. https://doi.org/10.1080/17405629.2011.643170

The Ministry of Communications and Information Technology (MCIT) (2018) ICT indicators in brief, November 2018 monthly issue. http://www. egyptictindicators.gov.eg/en/Publications/PublicationsDoc/lCT\%20Indicators\%2 Oin\%20brif\%20November\%202018\%20English.pdf. Accessed 30 Dec 2018.

UN Broadband Commission for Digital Development Working Group on Broadband and Gender (2015) Cyber violence against women and girls: a worldwide wake-up call. United Nations http://www.unwomen.org/ /media/ headquarters/attachments/sections/library/publications/2015/cyber_ violence_gender\%20report.pdf? $v=1 \& d=20150924 T 154259$. Accessed 15 Jan 2019.

West J (2014) Cyber-violence against women. Battered Women's Support Services https://www.bwss.org/cyber-violence-against-women/. Accessed 30 Jan 2019.

Winkelman SB, Early JO, Walker AD, Chu L, Yick-Flanagan A (2015) Exploring cyber harassment among women who use social media. Univ J Public Health 3(5):194-201. https://doi.org/10.13189/ujph.2015.030504

World Health Organization (2017) Violence against women. https://www.who.int/ news-room/fact-sheets/detail/violence-against-women. Accessed 30 Jan 2019.

\section{Publisher's Note}

Springer Nature remains neutral with regard to jurisdictional claims in published maps and institutional affiliations. 